\title{
A LEGISLAÇÃO BRASIlEIRA E OS DESAFIOS PARA A ADMINISTRAÇÃO PÚBLICA GARANTIR A FUNÇÃO SOCIAL DA PROPRIEDADE
}

\section{ARTIGO ORIGINAL}

OLIVEIRA, Francisca da Glória Menezes de ${ }^{1}$

SILVA, Maria Auxiliadora Santos ${ }^{2}$

CAVALCANTI, Maria de Fátima Ferreira Santos ${ }^{3}$

OLIVEIRA, Francisca da Glória Menezes de. SILVA, Maria Auxiliadora Santos. CAVALCANTI, Maria de Fátima Ferreira Santos. A legislação brasileira e os desafios para a administração pública garantir a função social da propriedade.

${ }^{1}$ Graduada em Letras Pela FACHUSC (Faculdade de Ciências Humanas do Sertão Central). Graduada em Direito pela FACESF ( Faculdade de Ciências Humanas e exatas do Sertão do São Francisco; Especialização em Direito Penal e Processo Penal pelo Instituto Elpídio Donizetti; mestranda na UNISANTOS - Campus Boqueirão Santos - SP - Programa de Mestrado em Direito Internacional em Direitos Humanos.

2 Graduada em Jornalismo e Comunicação Social (JORANLISMO) pela UFPB; graduada em DIREITO pela UNIPÊ (Centro Universitário de João Pessoa/PB); Especialização em Ordem, Cidadania pela FESMIP (Fundação Escola Superior da Paraíba); Especialização para carreira Jurídica, Curso preparatório para a Magistratua pela ESMA-PB (Escola Superior da Magistratura da Paraíba; mestranda na UNISANTOS - Campus Boqueirão Santos - SP - Programa de Mestrado em Direito Internacional em Direitos Humanos.

${ }^{3}$ Graduada em DIREITO pela UFPB; Especialização em Direito Administrativo, ESMA, ESMIP; mestranda na UNISANTOS - Campus Boqueirão Santos - SP Programa de Mestrado em Direito Internacional em Direitos Humanos. 
Revista Científica Multidisciplinar Núcleo do Conhecimento. Ano 04, Ed. 07, Vol. 05, pp. 69-88. Julho de 2019. ISSN: 2448-0959

\section{RESUMO}

O trabalho em tela propor-se-á a realizar uma breve análise acerca da garantia da efetividade da função social da propriedade pela Administração Pública. Os registros históricos dão conta que o conceito atual de função social da propriedade foi permeado por diversas etapas até que se chegassem aos conceitos mais justos condizentes com os princípios gerais dos direitos humanos e do direito à moradia com dignidade social. São inúmeros os conflitos urbanos flagranciados na sociedade brasileira atual. Alguns chamam a atenção pela forma estúpida com que os cidadãos foram tratados pelo Poder Público. A exclusão e supressão histórica da comunidade da Vila Autódromo no Rio de Janeiro é um exemplo que o poder público não zela pela preservação da dignidade humana consoante as previsões legais nacionais e internacionais. Outra barreira para que se efetive a função social da propriedade é no tocante à fragilidade das legislações nacionais serem postas em prática.

Palavras-chave: ineficiência, legislação, função social da propriedade, garantia da dignidade humana.

\section{INTRODUÇÃO}

No capítulo primeiro, traçaremos um breve histórico acerca da história da propriedade urbana no Brasil. Pode-se constatar que o conceito a que chegamos na atualidade foi permeado por diversas etapas. Em cada uma delas, verificaram-se enormes dificuldades para se implementar política urbana justa condizente com os princípios gerais dos direitos humanos e do direito à moradia com dignidade social. Os progressos referentes ao tema foram registrados praticamente a partir do início do século passado conforme relataremos no presente texto.

O segundo capítulo tratar-se-á de um conflito urbano concreto que provocou a exclusão e supressão histórica da comunidade da Vila Autódromo no Rio de Janeiro. 
Com o estudo do caso em tela, comprovar-se-á que o poder público não zela pela preservação da dignidade humana e o direito à moradia consoante as previsões estampadas em legislações nacionais e internacionais. Em síntese, o que se viu na remoção da Vila autódromo foi uma política de seletividade de poder aquisitivo.

No terceiro capítulo, teceremos, de forma breve, uma análise sobre os desafios enfrentados pela legislação brasileira nacional na manutenção da Função Social da Propriedade.

A temática será abordada a partir do método analítico, por meio de pesquisa teórica sustentada em bibliografia e consultas doutrinária e documentais sobre 0 aludido tema.

Tomamos como referencial teórico os autores: Washington de Barros Monteiro (2003), Luiz da Cunha Gonçalves (1952), Guilherme José Purvin de Figueiredo (2008), dentre outros, que nos apresentaram conceitos, exemplos de casos concretos de conflitos em decorrência da posse ou propriedade, bem como os princípios da Função Social da Propriedade, também o que traz a legislação constitucional vigente na seara do Direito Ambiental, Direito Internacional e Direitos Humanos.

Partimos da premissa de que a reflexão e o debate são salutares para a compreensão dos fenômenos sociais, ambientais, culturais, políticos e econômicos que ocorrem na sociedade contemporânea, especialmente comparando e entrelaçando conceitos, tendo como alvo a resolução dos problemas e questionamento na seara ambientalista e da qualidade de vida.

\section{EVOLUÇÃO HISTÓRICA DA PROPRIEDADE URBANA NO BRASIL}

A evolução histórica da propriedade urbana no Brasil passou por várias transformações durante o processo de urbanização. No decorrer desse processo houve época em que a urbanização era inexistente. Sobre isso Santos (1996, p.17) afirma: "A cidade' era bem mais uma emanação de poder longínquo, um desejo de 
marcar presença num país distante". Todavia, em outros momentos foram registradas intensa organização em decorrência da população rural.

De acordo com Diniz (2010, p.53):

No Brasil, a propriedade percorreu um longo processo de migração do patrimônio público para o privado, deixando a fundação do domínio da coroa portuguesa até sua posterior e gradual apropriação pelos particulares através de três maneiras distintas: usucapião, cartas de sesmarias e posses sobre terras devolutas, com a concentração de terras por senhores de escravos, constituindo aquilo que até hoje chamamos de latifúndio.

O processo de colonização do Brasil (séculos XXVI a XIX) foi caracterizado por restrições ao direito à propriedade. Apenas aqueles que eram agraciadas pelo rei, mediante doações, tinham o direito sobre a propriedade - processo esse denominado sesmarias. Nessa época, a função da propriedade não era social, mas, exclusivamente de produção econômica, que trazia benefícios para a coroa portuguesa. Até então pensava-se em transformar o Brasil em um grande latifúndio e não num país povoado. Sobre isso, Laranjeira (1975, p.87) afirma:

Certamente, a legislação avulsa, margeante das Ordenações, deixa transparecer vivamente que só a função econômica da terra colonial interessaria à Coroa, ávida de melhores rendimentos sobre nossas culturas. Por isso mesmo, quando mais importasse a Portugal a proliferação de grandes latifúndios - pois enormes tratos de terra sesmariada eram compatíveis com a lavoura canavieira do litoral e a pecuária extensiva dos sertões - daí se fez tábua rasa das normas legais existentes, sobremaneira as relativas à delimitação de cada sesmaria e às referentes concessões de mais de uma data.

Assim, durante o Brasil Colônia, Portugal evitava que houvesse crescimento no número de proprietários de terras. Dessa forma, o processo de urbanização no Brasil 
foi prejudicado. As cidades não tinham infraestrutura e não passavam de pequenos povoados.

Segundo Santos (1996, p.18):

O Brasil foi, durante muitos séculos, um grande arquipélago, formado por espaços que evoluíam segundo lógicas próprias, ditadas em grande parte por suas relações com o mundo exterior. Havia, sem dúvida, para cada um desses subespaços, polos dinâmicos internos.

A história da propriedade urbana no nosso país, a privatização do solo urbano, estão intrinsecamente ligados à mudança dos destinos da população que começou a migrar da zona rural para a zona urbana, em busca de uma vida melhor.

No início do processo de privatização do solo urbano, houve grandes distorções em virtude do sistema latifundiário monocultor. A população era em sua grande maioria rural. Com o fenômeno da migração, registrado no século $X X$, decorrente da industrialização brasileira, o perfil geográfico do Brasil começou a ser transformado radicalmente. Junto a essa mudança, surgiram alguns problemas importantes: a especulação imobiliária foi uma delas, provocando a favelização nas grandes cidades. Os imigrantes, os quais passaram a povoar a nossa nação, em sua maioria não dispunham de recursos para comprar um pedaço de chão sequer, muito menos uma moradia, tornando-os população socialmente excluída.

Segundo Santos (1996): "As favelas cresceram no Brasil, em virtude do número crescente de pessoas nas zonas urbanas oriundas da zona rural, consequência da falta de política de planejamento urbano, e também devido à especulação fundiária". Sendo assim, em virtude da crescente demanda da população, o modelo de propriedade passou por ajustes. A Constituição Federal de 1988 contribuiu positivamente para a solução de problemas relacionados ao desenvolvimento urbano. Assim, no art. 182 está previsto:

A política de desenvolvimento urbano, executada pelo Poder Público municipal, conforme diretrizes gerais fixadas em lei, tem por objetivo 
ordenar o pleno desenvolvimento das funções sociais da cidade e garantir o bem-estar de seus habitantes.

Desse modo, reconhece-se que o direito à propriedade tem fundamento social. A partir de então, Políticas Públicas direcionadas à moradia têm sido implementadas em todas as regiões do Brasil, beneficiando milhões de brasileiros.

É oportuno lembrar que o instituto da função social da propriedade entrou no âmbito jurídico no início do século XX. Já o instituto de direito à cidade, depois do ano 1968 , quando, pela primeira vez, o termo foi introduzido. Assim, foram garantidos os direitos de propriedade.

A Carta Magna de 1988 declara que: "É garantido o direito de propriedade", determinando, no inciso seguinte que: "A propriedade atenderá a sua função social" (BRASIL, 1988).

A Constituição Federal de 1988, de conformidade com as afirmações de Diniz (2010, p.178):

Elevou o princípio da função social ao patamar de alicerce da ordem econômica, e foi além, estabelecendo-o como direito fundamental no rol das cláusulas pétreas. Disciplinou o exercício da propriedade urbana no espectro da política urbanística e inseriu a regulação da propriedade rural no capítulo em que trata da política agrícola e fundiária. Instituiu a usucapião especial voltada à proteção da pequena propriedade e determinou regras para a aquisição da propriedade imobiliária por estrangeiros no Brasil.

Portanto, conclui-se, dessa breve retrospectiva histórica sobre a evolução da propriedade urbana no Brasil, que o processo de desenvolvimento urbano no nosso país foi, além de lento, cheio de períodos difíceis. Após um século do fim do período colonial, a história da evolução da propriedade urbana começou a registrar avanços sucessivos até a promulgação da Constituição Federal de 1988, que trouxe muitos 
benefícios para a propriedade privada em vários aspectos, tais como o social, o mais importante.

\section{CONFLITOS SOCIAIS URBANOS EM DECORRÊNCIA DE POSSE E PROPRIEDADE}

\subsection{VILA AUTÓDROMO - A EXCLUSÃO DE UMA COMUNIDADE}

As formas de assentamentos informais, as moradias inadequadas carentes de um mínimo de estrutura básica para atender às necessidades humanas são preocupações reais do Direito Internacional dos Direitos Humanos. Conforme ensinamentos de Trindade (1997), esse ramo da ciência jurídica tem-se projetado como autônomo e com características próprias. Seu alvo de proteção não é o Estado, mas sim os seres humanos. São inúmeros os instrumentos internacionais de âmbito globais e regionais que almejam proteger as pessoas das mais variadas formas de violências /injustiças sociais. ${ }^{[4]}$

Urge ressaltar que a DUHDH (Declaração Universal dos Direitos Humanos) de 1948, através da resolução 217-A da Assembleia Geral das Nações Unidas preconiza o seguinte:

\section{Artigo XVII}

1. Todo ser humano tem direito à propriedade, só ou em sociedade com outros.

2. Ninguém será arbitrariamente privado de sua propriedade.

\section{Artigo XXV}

1. Todo ser humano tem direito a um padrão de vida capaz de assegurarIhe, e a sua família, saúde e bem-estar, inclusive alimentação, vestuário, habitação, cuidados médicos e os serviços sociais indispensáveis, e direito à segurança em caso de desemprego, doença, invalidez, viuvez, 
velhice ou outros casos deperda dos meios de subsistência em circunstâncias fora de seu controle.

No tocante à definição do direito à cidade, A Carta Mundial pelo Direito à Cidade demonstra preocupação com os direitos das minorias suscetíveis às vulnerabilidades sociais, preceituando o que se segue:

ARTIGO I.

\section{DIREITO À CIDADE}

1. Todas as pessoas devem ter o direito a uma cidade sem discriminação de gênero, idade, raça, condições de saúde, renda, nacionalidade, etnia, condição migratória, orientação política, religiosa ou sexual, assim como preservar a memória e a identidade cultural em conformidade com os princípios e normas estabelecidos nessa Carta.

2. O Direito a Cidade é definido como o usufruto equitativo das cidades dentro dos princípios de sustentabilidade, democracia, equidade e justiça social. É um direito coletivo dos habitantes das cidades, em especial dos grupos vulneráveis e desfavorecidos, que thes confere legitimidade de ação e organização, baseado em seus usos e costumes, com o objetivo de alcançar o pleno exercício do direito à livre autodeterminação e a um padrão de vida adequado. ...

De outra banda, o manual elaborado em conjunto pela Organização das Nações Unidas (ONU) e pelo Alto Comissariado das Nações Unidas sobre Direitos Humanos no documento intitulado como O Direito à Moradia Adequada (The Right to Adequate Housing), assegura que as sociedades e os Estados devem garantir moradia sem riscos/ameaças de remoções arbitrárias, lazer, educação, água potável, ambiente saudável, proteção e outras necessidades básicas e essenciais aos grupos vulneráveis: idosos, crianças, deficientes, bem como aqueles com rendas insuficientes. 
É conveniente destacar que no Comentário Geral no 04 proveniente do Comitê dos Direitos Econômicos, Sociais e Culturais inserto na (Sexta Sessão, 1991), o qual trata acerca da garantia de moradia aos vulneráveis assegura os seguintes aspectos: segurança jurídica da posse, disponibilidade dos serviços materiais, etc.

O Direito à moradia digna além de estar regrado pelos documentos internacionais, a Carta Política de 1988 na sessão da Política Urbana enfatiza em seus arts. 182 e 183 o seguinte:

Art. 182. A política de desenvolvimento urbano, executada pelo poder público municipal, conforme diretrizes gerais fixadas em lei, tem por objetivo ordenar o pleno desenvolvimento das funções sociais da cidade e garantir o bem-estar de seus habitantes. (grifo nosso) $\S 1^{\circ}$ - O plano diretor, aprovado pela Câmara Municipal, obrigatório para cidades com mais de vinte mil habitantes, é o instrumento básico da política de desenvolvimento e de expansão urbana.

$\S 2^{\circ}$ - A propriedade urbana cumpre sua função social quando atende às exigências fundamentais de ordenação da cidade expressas no plano diretor.

$\S 3^{\circ}$ - As desapropriações de imóveis urbanos serão feitas com prévia e justa indenização em dinheiro. (grifo nosso)

\section{$(\ldots)$}

Art. 183. Aquele que possuir como sua área urbana de até duzentos e cinqüenta metros quadrados, por cinco anos, ininterruptamente e sem oposição, utilizando-a para sua moradia ou de sua família, adquirir-Ihe-á o domínio, desde que não seja proprietário de outro imóvel urbano ou rural. 
§ 3ำ - Os imóveis públicos não serão adquiridos por usucapião.

As previsões positivadas nas vastas documentações apontadas são importantes para assegurarem a realização de uma vida digna aos seres humanos, pois consoante as lições de Serrano Júnior (2012), a moradia não é somente um direito fundamental, mas também um direito de personalidade que visa à proteção integral do indivíduo.

Entretanto, tem-se observado que os megaeventos, como por exemplo as copas do mundo, jogos olímpicos, vêm gerando inúmeros conflitos relacionados ao direito de moradia, propriedade, posse. Em atendimento às desculpas do falso interesse público, são inúmeras as violações à dignidade humana, negando o direito de morar/residir no lugar em que as pessoas construíram sua história. A remoção da Vila Autódromo no Rio de Janeiro é um flagrante caso de arbitrariedade do poder público contra essa comunidade. $O$ que vimos foi a literalidade da supressão de histórias comuns construídas há longos anos.

A via-crúcis dessa comunidade de baixa renda iniciou-se nos anos 90, quando desde então o Poder Público promovia ameaças para removê-los de seu habitat, utilizandose do fundamento de que se pretendia salvaguardar o meio ambiente. Naback e Oliveira (2015), em seu trabalho de monografia, informa que a Fazenda Municipal ingressou com uma ação judicial para demolição das edificações da vila autódromo sob alegação de que a comunidade causava danos ambientais e urbanístico. Ocorre que não se requereu a extinção das construções de condomínios luxuosos e shoppings que estavam encravados no mesmo ambiente que o Município mencionava que pretendia proteger.

Com isso, infere-se que a real motivação para se provocar a extinção da comunidade foi eliminar, segregar, realizar uma "limpeza social" contra os mais vulneráveis daquele espaço urbano, a fim de atender aos anseios econômicos do mercado mobiliário. A agressiva realocação das famílias atingiu praticamente cem por cento da população. A agressiva extirpação daquela gente pode ser comprovada com o relato do Senhor Altair (ex-Presidente da Associação de Moradores da Vila Autódromo), a qual está registrada por Rolnik (2015, p.79): 
"O que o governador Carlos Lacerda disse para justificar a remoção é que a minha comunidade sujava a lagoa e fazia os peixes morrerem. Hoje a gente vê que aquilo é uma grande mentira, porque os peixes continuam morrendo. Eles queriam era uma limpeza social, colocar pedalinhos, embelezar a cidade, Fiquei dos 14 anos até os meus 35 anos ali na Cidade de Deus, que era para ser uma cidade modelo e na verdade virou um verdadeiro arsenal de guerra. Tu sabe o que é eu, já casado, ter que deitar com as minhas filhas no chão por causa de bala traçante? Até que um dia a gente é surpreendido de novo com a remoção por conta da Linha Amarela [via expressa de ligação do Aeroporto do Galeão com a Barra da Tijuca, construídos nos anos 1990]. Eu tava ali no meio do caminho e tinha de sair. De novo". (Altair Guimarães)

O testemunho do ex-morador (ex-líder) da Vila autódromo retrata um pouco do sofrimento que foi imposto àquela gente, bem como do drama vivido por eles. Nesse sentido escreve Carvalho, Ribeiro, Rodrigues (2016, p. 77) que todas as pessoas devem ter o direito de moradia sem a aflição das ameaças ilegais e indevidas. Essa garantia deverá variar de acordo com a cultura jurídica do país.

Segundo as lições registradas por Naback (2015, p. 109), a população da Vila autódromo estava protegida juridicamente pela Concessão do Direito real de uso por 99 anos, a qual poderia ter sido renovada pelo mesmo período de tempo. O título foi concedido pelo programa "Meu pé de chão" no governo de Manoel Brizola no quatriênio de 1991-1994. Ademais, a Lei Orgânica do Município do Rio de Janeiro (LOA/RJ-1990) e o Plano Diretor da cidade do Rio de Janeiro em seu artigo 44, III da Lei Complementar 16/1992 elegeram como princípio o da não remoção. Veja-se a transcrição do artigo em comento:

art. 44. $\S 1^{\circ} E$ estão sujeitas a realocação as favelas ou residências que ocupem:

I - áreas de risco; 
II - faixas marginais de proteção de águas superficiais;

III - faixa de proteção de adutoras e de redes elétricas de alta tensão;

IV - faixa de domínio de estradas federais, estaduais e municipais;

V - áreas de especial interesse ambiental ou unidades de conservação ambiental;

VI - vãos e pilares de viadutos, pontes e passarelas e áreas a estes adjacentes, quando oferecerem riscos à segurança individual e coletiva e inviabilizarem a implantação de serviços urbanos básicos;

VII - áreas que não possam ser dotadas de condições mínimas de urbanização e saneamento básico.

Pois bem, pelo o princípio da não remoção, a realocação da população seria medida de caráter excepcional. Como se percebe, a justificativa do dano ambiental não era verídica, uma vez que só buscava atingir os grupos vulneráveis financeiramente. Não havia questionamento de dano ambiental causado pelos luxuosos empreendimentos do mesmo local.

Em que pese todo arcabouço de proteção jurídica aos titulares da concessão de uso da Vila Autódromo, não foi suficiente para protegê-los da violência estatal. Naback (2015), registrou que dentre tantas desculpas para extinguir a Vila autódromo, em 2013, Eduardo Paes apresentou o projeto de demolição do bairro, tendo em vista que aquele espaço urbano seria necessário para construção das vias que dariam acesso ao Parque Olímpico e a Faixa Marginal de proteção ambiental da lagoa. A partir desse anúncio, recrudesceram os constrangimentos entre as famílias que deveriam ser cadastradas e os representantes da Prefeitura. Relata-se que houve confrontos de violência contra aqueles que resistiam à desocupação do local. Entretanto, nenhum sofrimento imprimido foi capaz de deter a política de seletividade racial e social. 
O poder público ignorou o título de posse dos moradores e os direitos pertencentes àquela comunidade. Violou a dignidade humana daquela coletividade. Tratou seus cidadãos como se fossem mercadorias com o condão de atender às especulações imobiliárias. O discurso de que os megaeventos esportivos fazem aquecer a economia e atrair investimentos para as cidades não pode ser preponderante para transgredir direitos fundamentais.

A definição do Direito Urbanístico se contrapõe às intervenções violentas nas comunidades vulneráveis socialmente. Para Lira $(2011$, p.6), a conceituação do Direito Urbanístico é editar normas com fins de organização da cidade, as quais sejam capazes de organizar o espaço urbano de modo justo, procurando garantir condições melhores de edificação, habitação, trabalho, circulação e lazer. Para Silva (2013, p. 49), propõe que o conjunto de normas que visa à organização dos espaços habitáveis deve garantir as melhores condições possíveis de vida na comunidade.

Nos ensinamentos de Vainer (2009, p.75-103), a agenda que desde então foi sendo delineada na cidade do Rio de Janeiro, mediante aliança do poder público com a iniciativa privada tem violado direitos fundamentais e sociais. A política neoliberal transformou o modelo de concepção urbana, dando lugar a uma gestão da cidade com interesses estritamente financeiros e especulativos. Assim, a cidade está sendo vista como uma "empresa".

É urgente que todas as propostas públicas de moradias devam ter propósitos de proteger às pessoas, e não de perseguições políticas urbanísticas contra seus administrados. Que os eventos de injustiças ocorridos com a realocação da comunidade da Vila Autódromo, sirva de modelo para não o repetir.

\section{DESAFIOS DA LEGISLAÇÃO AMBIENTAL BRASILEIRA NA MANUTENÇÃO DA FUNÇÃO SOCIAL DA PROPRIEDADE}

Consagrada, por excelência, na sociedade contemporânea como um direito subjetivo em constante construção social, a propriedade é, segundo os doutrinadores e ambientalistas, fruto maior da liberdade do homem. Essa construção transparece 
expressamente na vitória dos movimentos revolucionários liberais que originaram a feitura da Declaração de Independência dos Estados Unidos da América, datada de 4 de julho de 1776, como também da Declaração dos Direitos do Homem e do Cidadão, nascida, em 26 de agosto do mesmo ano, na França.

Para Washington de Barros Monteiro o direito de propriedade constitui "o mais importante e o mais sólido de todos os direitos subjetivos, o direito real por excelência, o eixo em torno do qual gravita o direito das coisas" (MONTEIRO, 2003). No entanto, na opinião do doutrinador Caio Mário da Silva Pereira, se torna tarefa difícil encontrar um conceito para propriedade, conforme a legislação nacional, "a propriedade mais se sente, do que se define".

A propriedade indicaria toda relação jurídica de apropriação de certo bem corpóreo ou incorpóreo. O direito de propriedade ainda pode receber a especial designação de domínio quando se referir, exclusivamente, a coisas corpóreas. O domínio é o gênero do qual a espécie é a propriedade

Na ótica do civilista Luiz da Cunha Gonçalves (1952) o direito de propriedade é aquele que uma pessoa singular ou coletiva efetivamente exerce numa coisa determinada em regra perpetuamente, de modo, normalmente absoluto, sempre exclusivo, e que todas as outras pessoas são obrigadas a respeitar.

Quanto à Função Social da Propriedade, na legislação brasileira, está caracterizada no que disciplina o artigo $5^{\circ}$, inciso XXIII, da Constituição Federal de 1988, cujo texto determina que "a propriedade atenderá a sua função social". Permeando o mesmo dispositivo legal existe, ainda, o artigo 170, incisos II e III (a Carta Magna afirmou a instituição da propriedade privada e a sua função social, como princípios da ordem econômica), determinando, ainda, o princípio da função social da propriedade com conteúdo definido em relação às propriedades urbana e rural, com sanções para não observância do referido princípio (artigos 182, 184 e 186).

A ideia de função social da propriedade constitui um marco histórico na evolução jurídica do direito de propriedade. Foi na passagem do século XIX para o XX, com a 
iniciativa de Leon Duguit, por meio de sua obra Las transformaciones del derecho público y privado, que a teoria da função social foi trazida para o direito de propriedade. (TÓRTOLA, 2010).

O festejado autor, Leon Duguit, contrapondo-se ao civilista, Luiz da Cunha Gonçalves, apregoa que, referente à seara patrimonial, a propriedade não tem mais um caráter absoluto e intangível. Duguit rejeita o conceito de propriedade como um direito subjetivo, não com o fim de negar a existência da propriedade privada, mas para esclarecer que ela não é um poder incondicionado e, sim, um poder jurídico que deve satisfazer necessidades individuais ou coletivas.

Guilherme José Purvin de Figueiredo (2008), analisando a função social da propriedade, salienta que tal função não sé é inerente ao Direito Ambiental, bem como, almeja atender aos fins sociais voltados às exigências do bem comum, pairando no ordenamento jurídico, como um mega princípio, que engloba os princípios da propriedade privada e da defesa ao meio ambiente. Para Figueiredo (2008, p. 98), preceitua que:

O princípio da função social da propriedade é voltado à consecução da finalidade última de toda ordem jurídica democrática, qual seja, a valorização da dignidade humana, que no plano da normativa ambiental é alcançada por regras que propiciem a vida com saúde e um meio ambiente natural e cultural que permita o desenvolvimento das potencialidades criativas do ser humano

Imperioso ressaltar a importante evolução histórica da legislação constitucional brasileira no tocante ao direito de propriedade, como também, à função social dela. Vale salientar as transformações nas noções de direito que têm regido as políticas de gestão urbana, territorial e ambiental ao longo do tempo.

Tendo em vista o papel estruturante em relação às demais legislações do país, a abordagem da série constitucional brasileira, a partir da primeira Constituição 
Republicana de 1891, até a atual de 1988, permite observar importantes transformações no decorrer da história.

Além dos novos entendimentos em relação ao direito de propriedade, as mesmas condições transformadoras estão presentes nas legislações que regem a política urbana e a ambiental. Nesse sentido, Silva e Teixeira (2017, p.126) leciona:

Nesses temas, podem ser identificadas situações que partem de um direito individual, pleno e absoluto, passando por um processo de relativização associado às noções de interesse público ou coletivo, até as concepções mais recentes, presentes na Constituição Federal de 1988, em relação ao direito social à moradia, aos direitos decorrentes do princípio da função social da cidade e da propriedade e ao meio ambiente ecologicamente equilibrado, bem de uso comum do povo.

De acordo com doutrinadores na área, e sendo reconhecido pelo ordenamento jurídico pátrio, o exercício dos direitos inerentes à propriedade não pode ser protegido com vistas a garantir exclusivamente a satisfação dos interesses do proprietário, como também, a função da propriedade, que se torna social.

Por conta dessas transformações surge uma série de consequências legais, apontadas por Figueiredo (2008), quais sejam: 1) legitima-se a vedação ao proprietário do exercício de determinadas faculdades; 2) cria-se "um complexo de condições para que o proprietário possa exercer seus poderes" e 3) o proprietário passa a ser obrigado a exercer determinados direitos elementares de domínio.

Além disso, a Magna Carta de 1988 disciplina a questão da função social da propriedade, apontando a distinção entre conforme se trate de propriedade urbana ou rural. O texto constitucional, no artigo $182, \S 2^{\circ}$, determina que "A propriedade urbana cumpre sua função social quando atende às exigências fundamentais de ordenação da cidade expressas no plano diretor."

Por sua vez, o plano diretor, elencado nos artigos 39 e seguintes da Lei no 10.257/2001, (Estatuto da Cidade), torna-se obrigatório para as cidades com mais de 
20 mil habitantes ou, ainda, para aquelas em que haja algum interesse especial, conforme determinado expressamente na lei.

É conveniente transcrever a ideia de Tórtola (2010, p.149) quando afirma que:

É instrumento básico da política de desenvolvimento e expansão urbana, e as exigências nele expressas buscam assegurar o atendimento das necessidades dos cidadãos quanto à qualidade de vida, à justiça social e ao desenvolvimento das atividades econômicas. Seu integral atendimento, portanto, caracteriza o cumprimento da função social da propriedade urbana, que busca alcançar o interesse geral da coletividade, e não de pessoas individualmente consideradas".

Manter a Função Social da Propriedade em meio aos avanços e modificações constantes ocasionados pela voraz Globalização do Desenvolvimento Econômico, e os interesses políticos, tendo como palco uma sociedade integralizada, permeada de mudanças, é um desafio, tanto para os gestores (municipais, estaduais e União), bem como, para os legisladores. A eficácia da legislação nacional é sempre posta em xeque-mate, especialmente quando se trata do cumprimento da letra fria da lei, no que concerne à manutenção da harmonia entre a manutenção da função social da propriedade, e a preservação ambiental.

\section{CONCLUSÃO}

Diante do exposto, pode-se inferir que a história da propriedade no Brasil (independente do momento histórico) sempre redundou em inúmeros conflitos sociais. Entretanto, alguns acontecimentos ainda geram mais ignomínias do que outros. É inconcebível e inaceitável que algumas políticas públicas adotadas estejam apenas mascaradas pelos bons desígnios do respeito aos seres humanos.

É com pesar que se pode concluir que a política urbanística para exclusão da comunidade Vila Autódromo foi uma agressão à dignidade humana dos moradores. Esse protótipo de intervenção deve ser repudiado pela sociedade local e também pela 
comunidade internacional. A parceria público-privada para as intervenções urbanísticas realizadas na cidade do Rio de Janeiro mostrou-se cruel, desumana, claramente viciada por interesses imobiliários. Observou-se que as normas de caráter ambiental e urbanísticas foram "adaptadas ou manejadas" a interesses econômicos.

O evento das Olimpíadas de 2016 poderia ter sido viabilizado e realizado, sem que os direitos referentes à proteção social da moradia fossem violados. As manipulações legislativas somente contribuem para um acirramento das diferenças raciais, sociais e territoriais, segregando principalmente as pessoas pela situação financeira.

Mister ressaltar o fato de que a propriedade privada só pode existir e ser protegida se cumprir sua função social, o que se dá, entre outros requisitos, com a proteção e especial cuidado do meio ambiente, bem de indiscutível preciosidade. Nas palavras de Tórtola (2010, p.73), é importante anotar que:

A qualidade ambiental é extremamente necessária para possibilitar, como consequência lógica, uma sadia qualidade de vida para as presentes gerações e a viabilidade de existência das futuras. $O$ tempo urge e não podemos esperar a boa-fé de terceiros em tomar alguma providência para minorar os efeitos devastadores das intervenções antrópicas lesivas ao meio ambiente

Por derradeiro, consideramos que muito há de ser pesquisado sobre essa temática, principalmente no que se refere aos desafios que a legislação nacional ambientalista enfrenta, quando da interpretação e aplicação da lei. O percurso na produção deste artigo revelou o quanto é delicado e difícil a proteção ambiental andar harmonizada com a dignidade humana e a preservação da vida ecologicamente adequada.

\section{REFERÊNCIAS}

A FUNÇÃO SOCIOAMBIENTAL DA PROPRIEDADE https://emporiododireito.com.br/leitura/a-funcao-socioambiental-da-propriedade Acesso em 19 de abril de 2019. 
A propriedade e sua função social e ambiental - http://www.ambitojuridico.com.br/site/index.php?n_link=revista_artigos_leitura\&artigo_id=8486. Acesso em 19 de abril de 2019.

CONSENTINO, Renato; JUNIOR, Orlando (orientador). Barra da Tijuca e o Projeto Olímpico: a cidade e o capital. Rio de Janeiro, 2015. 152p. Dissertação de mestrado Universidade Federal do Rio de Janeiro; Instituto de Pesquisa e Planejamento Urbano e Regional

\section{DA FUNÇÃO SOCIAL À FUNÇÃO AMBIENTAL DA PROPRIEDADE: AS ÁREAS DE PROTEÇÃo PERMANENTE E RESERVAS LEGAIS NO NOVO Código} FLORESTAL - http://www.publicadireito.com.br/artigos/?cod=13d763a5838ca85a Acesso em 19 de abril de 2019.

DESAFIOS DA GESTÃo URBANA E AMBIENTAL DIANTE DE - Desafios e perspectivas do direito ambiental em face da globalização dos riscos ambientais e socioeconômicos

https://andersoncruz5.jusbrasil.com.br/artigos/458932491/desafios-e-perspectivasdo-direito-ambiental-em-face-da-globalizacao-dos-riscos-ambientais-esocioeconomicos?ref=topic_feed - Acesso em 19 de abril de 2019.

DINIZ, Maria Helena. Sistemas de registros de imóveis. São Paulo. Saraiva, 2010.

FIGUeIREDO, Guilherme José Purvin de. A Propriedade no Direito Ambiental. Revista, atualizada e ampliada, 3ª ed., São Paulo: Revista dos Tribunais, 2008.

GONÇALVES, Luis da Cunha. Da propriedade e da posse. Tratado de Direito Civil. $2^{\mathrm{a}}$ ed., São Paulo: Max Limonad, s.d., v. XI, t. I., 1952.

LARANJEIRA, Raymundo. Propedêutica do Direito Agrário. São Paulo: LTR, 1975.

LEI COMPLEMENTAR № 054, DE 23 DE DEZEMBRO DE 2008 - PLANO DIRETOR DE JOÃO PESSOA - $\quad$ http://www.joaopessoa.pb.gov.br/portal/wp- 
content/uploads/2012/04/LC-054-DE-2008-Adequacao-do-Plano-Diretor-ao-Estatutoda-Cidade.pdf - Acesso em 19 de abril de 2019.

LIRA, Ricardo Pereira. Direito Urbanístico, Estatuto da Cidade e regularização fundiária. In: COUTINHO, Ronaldo; BONIZZATO, Luigi. 2. a ed. Direito da cidade: novas concepções sobre as relações jurídicas no espaço social urbano. Rio de Janeiro: Lumen Juris, 2011, p. 6.

MONTEIRO, Washington de Barros. Curso de Direito Civil. Atualizada por Carlos Alberto Dabus Maluf, 37ª ed., São Paulo: Saraiva, 2003, v. 3.

NABACK, Clarissa Pires de Almeida; OLIVEIRA, Thula (orientadora). Remoções biopolíticas: o habitar e a resistência da Vila Autódromo. Dissertação de mestrado. Rio de Janeiro: PUC, Departamento de Direito, 2015.

O direito de propriedade em face da preservação ambiental file://C:/Users/USER/Downloads/22-39-1-SM.pdf. Acesso em 19 de abril de 2019.

ROLNIK, Raquel. Guerra dos Lugares: A colonização da terra e da moradia na era das finanças. 1. a ed. São Paulo: Bomtempo, 2015.

SANTOS, Milton. A Urbanização Brasileira. 3 ed. São Paulo: Hucitec Editora, 1996.

SERRANO JÚNIOR, Odoné. O direito humano fundamental à moradia digna: exigibilidade, universalização e políticas públicas para o desenvolvimento. Curitiba: Juruá, 2012.)

SILVA, José Afonso. Direito Urbanístico Brasileiro. 7.ㄹ ed. São Paulo: Malheiros, 2013, p. 49

TRANSFORMAÇÕES NO DIREITO DE PROPRIEDADE NO BRASIL http://www.scielo.br/pdf/asoc/v20n4/pt_1809-4422-asoc-20-04-00001.pdf - Acesso em 19 de abril de 2019. 
TRINDADE, Antonio Augusto Cançado. Tratado de Direito Internacional dos Direitos Humanos, Volume I, Fabris Editor, Porto Alegre, 1997, p. 20

VAINER, Carlos. Pátria, empresa e mercadoria: a estratégia discursiva do Planejamento Estratégico Urbano. In: ARANTES, O.; MARICATO, E.; VAINER, C. B. A Cidade do Pensamento Único. Desmanchando Consensos. 5a ed. Petrópolis: Vozes, 2009, p. 75-103.

4. TRINDADE, Antonio Augusto Cançado. Tratado de Direito Internacional dos Direitos Humanos, Volume I, Fabris Editor, Porto Alegre, 1997, p. 20.

Enviado: Junho, 2019.

Aprovado: Julho, 2019. 